\title{
MODEL PENGEMBANGAN KEPROFESIAN BERKELANJUTAN (PKB) BERBASIS SEKOLAH PADA GURU SEKOLAH DASAR (SCHOOL BASED CONTINOUS PROFESSIONAL DEVELOPMENT MODEL FOR PREMARY SCHOOL TEACHERS)
}

\author{
Junaidin Basri \\ STAI Al-Musaddadiyah Garut \\ junaidin.basri@stai-musaddadiyah.ac.id \\ Udin Sa'ud \\ Universitas Pendidikan Indonesia \\ udin.saud@upi.edu \\ Asep Suryana \\ Universitas Pendidikan Indonesia \\ doef@upi.edu
}

\begin{abstract}
Abstrack
The implementation of the Continuous Professional Development (PKB) program in improving the quality of primary school teachers in Garut Regency, West Java Province, Indonesia, has not been effective. The research objectives are: (1) to find out the existing PKB program planning carried out by elementary school teachers. (2) to find out the results and impact of the implementation of the PKB program on elementary school teachers, (3) to find a hypothetical model of $P K B$ activities that is more effective for elementary school teachers. The method used is a qualitative method with a case study approach. Data were obtained through observation, observation, interviews and review of documents with research participants as many as 3 elementary schools representing 3 teacher working groups $(K K G)$. Furthermore, the data were analyzed through transcription, data organization, recognition, coding and triingualization.

The results of the study found that the Continuing Professional Development $(P K B)$ program for elementary school teachers had not been effective in terms of planning, implementing, evaluating, organizing, and planning follow-up aspects. The resulting impact is only in the aspect of teacher self-development which has increased, while the teacher research culture is still low. To overcome this gap, the researcher offers a hypothetical model of School-Based Continuous Professional Development (PKB) as an alternative model to support the implementation of the existing KKG (Teacher Working Group)-based PKB.
\end{abstract}

Keywords: Teacher, CPD (Continous Professional Development), School Based 


\begin{abstract}
Abstrak
Pelaksanaan program Pengembangan Keprofesian Berkelanjutan (PKB) dalam meningkatkan mutu guru sekolah dasar di Kabupaten Garut Provinsi Jawa Barat Indonesia, belum berjalan efektif. Adapun tujuan penelitian adalah: (1) untuk mengetahui eksisting perencanaan program PKB yang dilaksanakan oleh guru sekolah dasar. (2) untuk mengetahui hasil dan dampak dari pelaksanaan program PKB pada guru sekolah dasar, (3) untuk menemukan model hipotetik kegiatan PKB yang lebih efektif bagi guru sekolah dasar. Metode yang digunakan adalah metode kualitatif dengan pendekatan studi kasus. Data diperoleh melalui pengamatan, observasi, wawancara dan kaji dokumen dengan partisipan penelitian sebanyak 3 sekolah dasar yang mewakili 3 kelompok kerja guru (KKG). Selanjutnya data di analisis melalui transkripsi, pengorganisasian data, pengenalan, koding dan tringualisasi.

Hasil penelitian menemukan bahwa program Pengembangan Keprofesian Berkelanjutan (PKB) bagi guru sekolah dasar belum efektif terkait aspek perencanaan, pelaksanaan, evaluasi, pengorganisasian, dan rencana tindak lanjut. Dampak yang dihasilkan hanya pada aspek pengembangan diri guru yang meningkat, sedangkan budaya riset guru masih rendah. Untuk mengatasi kesenjangan tersebut, peneliti menawarkan model hipotetik Pengembangan Keprofesian Berkelanjutan (PKB) Berbasis Sekolah sebagai model alternatif dalam mendukung pelaksanaan PKB berbasis KKG (Kelompok Kerja Guru) yang sudah ada.
\end{abstract}

Kata Kunci: Guru, CPD (Continous Professional Development), Berbasis Sekolah 


\section{Pendahuluan}

Persoalan mutu pendidikan di Indonesia menjadi salah satu masalah yang serius terkait mutu lulusan dalam berbagai jenjang pendidikan termasuk pendidikan dasar. Program Pengembangan Keprofesian Berkelanjutan (PKB) dikembangkan atas dasar profil kinerja guru yang masih rendah, sehingga dibutuhkan kegiatan PKB agar kompetensi guru mengalami peningkatan dalam memberikan layanan pembelajaran yang berkualitas pada siswa.

Upaya yang dilakukan oleh Dinas Pendidikan Kabupaten Garut dan para kepala sekolah dalam meningkatkan mutu guru melalui program Pengembangan Keprofesian Berkelanjutan (PKB) belum berdampak luas terhadap kemampuan guru dalam mengembangkan karya ilmiah dan karya inovatif, akan tetapi sudah berdampak terhadap pengembangan diri guru, sehingga belum berdampak luas terhadap peningkatan mutu sekolah dasar.

Permasalahan tersebut terjadi karena lemahnya aspek perencanaan dan pelaksanaan kegiatan PKB yang di dominasi oleh Dinas Pendidikan Kabupaten Garut Bidang Guru dan Tenaga Kependidikan, serta Kelompok Kerja Guru (KKG). Selain itu aspek keorganisasian Program Pengembangan Keprofesian Berkelanjutan (PKB) mulai dari tingkat Kabupaten hingga di sekolah dasar belum terlembagakan secara optimal, dampaknya program PKB tidak terkelola dengan baik oleh guru di masing-masing sekolah.

Berdasarkan latar belakang di atas, maka peneliti merumuskan pertanyaan penelitian sebagai berikut:

1. Bagaimana eksisting perencanaan kegiatan Pengembangan Keprofesian Berkelanjutan (PKB) oleh Guru Sekolah Dasar di Kabupaten Garut

2. Bagaimana hasil dan dampak dari pelaksanaan Pengembangan Keprofesian Berkelanjutan (PKB) bagi Guru Sekolah Dasar

3. Menemukan Model Hipotetik yang tepat dalam meningkatkan Program Pengembangan Keprofesian Berkelanjutan (PKB) bagi Guru Sekolah Dasar yang efektif.

Adapun tujuan dari penelitian ini, sebagai berikut:

1. Untuk menganalisis kondisi eksisting perencanaan dan pelaksanaan program Pengembangan Keprofesian Berkelanjutan (PKB) oleh Guru Sekolah Dasar

2. Untuk menganalisis hasil dan dampak dari program Pengembangan Keprofesian Berkelanjutan (PKB) di Sekolah Dasar

3. Untuk menghasilkan model hipotetik pelaksanaan Pengembangan Keprofesian Berkelanjutan (PKB) bagi Guru sekolah Dasar yang lebih efektif.

\section{Tinjauan Pustaka}

\section{Program Pengembangan Keprofesian Berkelanjutan (PKB)}

Berdasarkan kajian literatur yang telah dilakukan, peneliti menemukan beberapa hasil penelitian pada jurnal nasional maupun internasional tentang Implementasi Pengembangan Keprofesian Berkelanjutan (PKB) bagi guru. Secara umum hasil penelitiannya lebih menitip beratkan pada aspek konsep PKB, implementasinya, dan dampakya bagi guru di sekolah. Adapun yang menjadi pembeda dalam penelitian ini adalah secara khusus mengkaji tentang eksisting proses perencanaan dan kegiatan PKB bagi guru di sekolah dasar, dampak dan hasilnya dari pelaksanaan PKB bagi Guru sekolah dasar, serta menemukan model 
hipotetik yang tepat sebagai upaya meningkatkan program pengembangan Keprofesian Berkelanjutan (PKB) yang efektif dalam meningkatkan mutu guru dan mutu sekolah secara bersamaan.

Pengembangan Keprofesian Berkelanjutan (PKB) sebagai upaya nyata yang terstruktur dan berkelanjutan dalam meningkatkan kualitas guru secara individual dan organisasi pembelajaran secara kelembagaan. Hasil studi literatur ditemukan beberapa negara yang telah mengimplementasikan PKB dapat meningkatkan mutu guru, antaralain negara Irlandia, Scotlandia dan Inggris.

Di Irlandia; merujuk pada hasil penelitian yang dilakukan oleh (Cathal de Paor \& Timothy R. N. Murphy, 2018) dengan judul penelitian: Teachers' views on research as a model of CPD: implications for policy, yang mana peneliti ingin mengungkapkan tentang kontribusi CPD dalam meningkatkan rendahnya patisipasi riset guru di sekolah. Langkah operasional yang dilakukan di Irlandia adalah melakukan kolaboratif antar sekolah, guru dan dukungan birokrasi pendidikan melalui Model Training, Penghargaan, Standar Monitoring, dan Pendampingan yang Transformatife. Sementara itu di Skotlandia merujuk pada penelitian yang dilakukan oleh (Aileen Kennedy, 2011) dengan judul penelitiannya: Collaborative continuing professional development (CPD) for teachers in Scotland: aspirations, opportunities and barriers menyimpulkan bahwa Model Formal, Informal, Planned and Incidental. Berbeda halnya dengan pelaksanaan CPD di England, dengan merujuk pada penelitian yang dilakukan oleh (Ciaran Sugrue \& Sefika Mertkan, 2017) dengan judul : Professional responsibility, accountability and performativity among teachers: the leavening influence of CPD, Teachers and Teaching. Hasil penelitiannya menyimpulkan bahwa, dengan CPD dapat meningkatkan proses transformasi iklim kerja untuk menjaga, memelihara dan mengembangkan tanggung jawab profesionalisme yang menghasilkan kualitas pembelajaran yang efektif.

Merujuk pada hasil penelitian di tiga negara tersebut, penelitian ini mencoba melihat perbandingan dengan praktek pelaksanaan PKB di Indonesia, yakni dengan memperkuat kebijakan pemerintah tentang pentingnya manajemen berbasis sekolah sehingga memiliki posisi yang sangat penting guna menciptakan temuan teoritis dan praktis sebagai sandaran model Pengembangan Keprofesian Berkelanjutan (PKB) di Indonesia dalam meningkatkan mutu guru dan mutu sekolah.

Selain itu hasil penelitian CPD menunjukkan bahwa kepentingan, dampak dan tantangan CPD berpengaruh terhadap keberhasilan program CPD. Komponen penting CPD dan dampak program CPD dapat mempengaruhi keberhasilan program CPD di sekolah (Juneau Flor E.Julian \& Fred B.Ruiz, 2020). Hasil penelitian Geldenhuys \& Oosthuizen (2015) menguraikan isu tantangan yang perlu dihadapi dalam pengembangan keprofesian berkelanjutan (PKB) di sekolah antaralain; kurangnya kontribusi manajemen sekolah terhadap CPD guru, partisipasi guru yang kurang dalam kegiatan CPD, tidak menghasilkan pengetahuan baru yang didapatkan oleh guru dan faktor-faktor lain yang menghalangi guru untuk mengambil bagian secara efektif dalam pelaksanaan CPD. 


\section{Manajemen Berbasis Sekolah}

Manajemen sekolah merupakan proses mengelola sekolah melalui perencanaan, pengorganisasian, pengarahan dan pengawasan sekolah agar mencapai tujuan pendidikan yang telah ditetapkan (George R. Terry, 2005). Secara umum ada empat fungsi manajemen yaitu fungsi perencanaan, pengorganisasian, pengarahan dan fungsi pengendalian. Untuk fungsi pengorganisasian terdapat pula fungsi pembentukan staf (Li et al., 2018) Manajemen sekolah menjadi salah satu cara untuk mengembangkan kapasitas yang dimiliki sekolah dalam meningkatkan kemampuan secara individu, organisasi dan sistem dalam menjalankan fungsinya secara efektif, efisien dan berkelanjutan (Asif et al., 2011).

Manajemen sekolah menjadi sebuah produk yang dihasilkan melalui beberapa kebijakan sekolah, dibuktikan dengan tindakan untuk mengintervensi perilaku warga sekolah dan dikembangkan melalui pendekatan kedisiplinan yang tinggi baik di dalam maupun di luar proses pembelajaran (Cameron, 2006). Manajemen sekolah merupakan sebuah reaksi dari prinsip manajemen yang berafiliasi dalam gerakan meningkatkan hubungan sosial secara berkelanjutan (Nolan, 2017).

Sedangkan (Garrett (2012) mengungkapkan bahwa manajemen sekolah menjadi sebuah kebutuhan dan cara untuk merefleksikan proses dan mengidentifikasi hasil yang dijalankan oleh sekolah tersebut. Memahami manajemen sekolah, yang harus diperhatikan adalah melihat proses yang berlangsung dalam sekolah, yang dapat memberikan gambaran untuk mengetahui bagaimana cara untuk membuat sekolah berhasil secara efektif dan efisien (Sutapa, 2014).

Komponen yang terlibat dalam proses manajemen sekolah adalah kepemimpinan, pengambilan keputusan, keterlibatan tenaga kependidikan, alokasi sumberdaya, implementasi kurikulum, lingkungan sekolah, komunikasi, dan teknologi sebagai tujuan sekolah (Gustafsson \& Taylor, 2018). Konsekuensi dari perubahan dimensi manajemen sekolah adalah melakukan adaptasi dan pembaharuan, dengan prinsip mutu sebagai sebuah budaya yang dihasilkan sekolah.

Oleh karena itu mengimplementasikan prinsip-prinsip manajemen dalam pengelolaan sekolah menjadi sebuah keharusan agar mutu sekolah dapat meningkat.

\section{Metode}

Metode yang digunakan dalam penelitian ini adalah metode kualitatif dengan kategori studi kasus sehingga peneliti dapat menemukan gambaran yang sesungguhnya terkait pelaksanaan program Pengembangan Keprofesian Berkelanjutan (PKB) bagi Guru Sekolah Dasar di Kabupaten Garut dari tahun 2015-2019 (Creswell, 2018).

Penelitian ini dilakukan pada tiga sekolah dasar di Kabupaten Garut, Jawa Barat, yakni Guru SDIT Attika Musaddad: 39 guru, SDN Kota Kulon 2: 18 guru dan SDIT Persis Tarogong: 45 guru. Kepala Sekolah Dasar: 3 orang, Koordinator Kelompok Kerja Guru: 3 orang, Faslitator PKB Sekolah: 3 orang, Unsur Dinas Pendidikan Kabupaten Garut: 3 orang.

Teknik pengolahan data dengan mangacu pada pendapat (Creswell, 2018) yakni dari pengumpulan data mentah, pengorganisasian dan persiapan data untuk 
di analisa,, membaca seluruh data, melakukan coding dan membagikan kedalam kelompok tema dan deskripsi. Teknik analisis data dilakukan sejak pengumpulan data sampai selesai, saat melakukan wawancara peneliti sudah melakukan analisis terhadap jawaban yang diwawancara. Jika hasil analisis jawaban partisipan belum memuaskan, maka peneliti melakukan pertanyaan lagi sampai tahap tertentu bahwa data sudah sesuai dengan kebutuhan.

Adapun langkah yang dilakukan dalam proses pengolahan data antaralain: verifikasi data, kategorisasi data, memeriksa kelengkapan data dari seluruh partisipan, kemudian dilakukan pengecekkan ulang terhadap seluruh pertanyaan dengan kembali melakukan verifikasi, kategorisasi dan pengecekkan ulang kelengkapannya. Selanjutnya peneliti menarasikan hasil temuan dan pembahasan hasil temuan yang di dukung hasil penelitian terdahulu, teori dan konsep yang relevan dengan masalah yang sedang dibahas, kemudian menarik kesimpulan.

\section{Hasil Pembahasan}

\section{Isi Hasil dan Pembahasan}

Selama kurang lebih tujuh bulan melakukan penelitian, ditemukan dua masalah pokok yakni; pertama berkaitan dengan eksisting pelaksanaan program pengembangan keprofesian berkelanjutan bagi guru sekolah dasar yang belum efektif pelaksanaannya, dan kedua hasil pelaksanaan PKB belum berdampak pada peningkatan budaya riset bagi guru sekolah dasar, dan hanya berdampak terhadap peningkatan pengembangan diri guru secara personal, sehingga belum berdampak luas terhadap peningkatan mutu sekolah.

\section{Eksisting Perencanaan Pengembangan Keprofesan Berkelanjutan (PKB)}

Berdasarkan temuan penelitian yang dilakukan, terdapat 3 (tiga) sekolah yang mewakili 3 Kelompok Kerja Guru (KKG) yang berbeda pihak sekolah dasar belum memiliki program perencanaan pengembangan guru secara sistematis, hal ini dapat dilihat dari beberapa indikator diantaranya: (a) belum adanya rencana program kerja pengembangan guru yang terdokumentasikan secara baik sebagai bagian dari program kerja sekolah. (b) perencanaan kegiatan program Pengembangan Keprofesian Guru (PKB) masih dilakukan oleh Kelompok Kerja Guru (KKG) yang merupakan organisasi adhok profesi guru pada tingkat kecamatan, sementara dalam buku Pedoman PKB sekolah boleh melakukan kegiatan perencanaan PKB secara mandiri, lintas sekolah dan bermitra dengan universitas atau lembaga pelatihan lainnya yang kompeten.

Proses perencanaan kegiatan PKB di sekolah dasar sangat sederhana, dimana panitia yang tergabung dalam KKG membuat proposal kegiatan $\mathrm{PKB}$, (data panitia penyelenggara PKB di KKG dan Proposal Kegiatan) berkoordinasi dengan koordinator Disdik ditingkat kecamatan, setelah mendapatkan persetujuan, panitia akan berkoordinasi dengan pihak Disdik Kabupaten Garut, hal tersebut dilakukan agar mempermudah dalam melakukan proses post tes dimana pihak Disdik bisa membantu untuk menggunakan fasilitas laboratorim komputer yang saat ini baru dimiliki oleh SMP, SMA maupun SMK.

\section{Dampak Pelaksanaan PKB bagi Guru Sekolah Dasar}

Berkaitan dengan hasil dan dampak dari pelaksanaan kegiatan PKB bagi Guru Sekolah Dasar di Kabupaten Garut, secara khusus lebih berorientasi pada dukungan pengembangan diri guru. Sedangkan aspek kemampuan guru dalam 
membuat karya ilmiah belum menjadi program prioritas guru dan sekolah. Indikatornya masih sedikit guru yang sudah mampu membuat karya ilmiah dan membuat karya inovasi.

\section{Isi Hasil Pembahasan}

Penelitian Pengembangan Keprofesian Berkelanjutan (PKB) bagi guru Sekolah Dasar di Kabupaten Garut, hasilnya secara umum belum terlaksana dengan baik, sehingga belum berdampak terhadap terhadap peningkatan mutu guru.

Penelitian tentang pengembangan guru yang berorientasi pada peningkatan profesionalisme guru pada umumnya belum optimal, hal tersebut terjadi karena kegiatan pengembangan profesional yang dilakukan selama ini ditemukan tidak efektif dan dinilai tidak relevan dengan kebutuhan guru. Pandangan ini sejalan dengan hasil penelitian (Van Veen, K., Zwart, R., \& Meirink, 2012). Sedangan hasil penelitian menyimpulkan bahwa program CPD dapat meningkatkan pengembangan profesional guru secara efektif (Opfer \& Pedder, 2011).

Pengembangan Keprofesian Berkelanjutan (PKB) sangat penting bagi guru dalam meningkatkan cara dan metode mengajar secara optimal, pandangan ini sejalan dengan hasil penelitian yang dilakukan oleh (van den Bergh et al., 2015). Melalui Program Pengembangan Keprofesian Berkelanjutan (PKB) para guru dapat memperoleh pengetahuan tentang proses pembelajaran sehingga dapat meningkatkan perubahan kemampuan profesional guru terkait aspek pengetahuan dan praktisnya (Aileen Kennedy, 2006; Murphy \& de Paor, 2017; van den Bergh et al., 2015). Kegiatan pengembangan profesional harus dibangun di atas pengetahuan dan kebutuhan keyakinan guru, masalah yang dirasakan, dan praktik kelas (Opfer \& Pedder, 2011) Mansour, N., Heba, E. D., Alshamrani, S., \& Aldahmash (2014).

Kedua pandangan di atas menunjukan bahwa dari seluruh rangkaian pelaksanaan PKB, mulai dari aspek perencanaan, pelaksanaan, pengawasan, evaluasi dan refleksi belum berjalan secara optimal. Untuk menjawab masih rendahnya implementasi PKB bagi guru dibutuhkan model pelaksanaan PKB yang bisa mengoptimalkan fungsi manajemen. Kehadiran manajemen dalam organisasi PKB agar tujuan tercapai dengan efektif dan efisien dengan cara mengoptimalkan fungsi: planning, organizing, motivating, innovating dan controlling (Engkoswara \& Aan Komariah, 2010).

PKB sebagai salah satu upaya yang dilakukan Kementrian Pendidikan dan Kebudayaan melalui Direktorat Guru dan Tenaga Kependidikan untuk meningkatkan profesionalisme guru perlu dilaksanakan secara konsisten oleh seluruh pelaksana kegiatan dalam seluruh tingkatan satuan pendidikan, termasuk dinas Pendidikan Kabupaten sebagai aktor implementator kebijakan nasional, kepala sekolah dan para guru. Konsep PKB yang menekankan pentingnya pemberdayaan guru sebagai sebuah profesi yang kompetitif di era persaingan global saat ini, dibutuhkan kesadaran individu dan kolektif para guru dalam meningkatkan kompetensinya melalui perencanaan kegiatan PKB yang matang, pelaksanaan PKB yang berbasis pada kebutuhan, evaluasi berorientasi pada kinerja yang akuntabel, serta refleksi yang simultan dan berkelanjutan, sehingga melahirkan pelaksanaan PKB yang professional sehingga berdampak terhadap peningkatan mutu guru. 
Sebagai solusi dari belum efektifnya pelaksanaan pengembangan keprofesian berkelanjutan (PKB) bagi guru sekolah dasar yang belum berdampak terhadap peningkatan mutu profil guru dan prestasi siswa serta mutu sekolah, maka dibutuhkan alternatif model Pengembangan Keprofesian Berkelanjutan (PKB) yang berbasis pada manajemen sekolah, sehingga dapat mendukung pelaksanaan PKB yang sudah ada melalui Kelompok Kerja Guru (KKG). Sebagaimana dalam diagram model Pengembangan Keprofesian Berbasis (PKB) berbasis Sekolah, berikut ini:

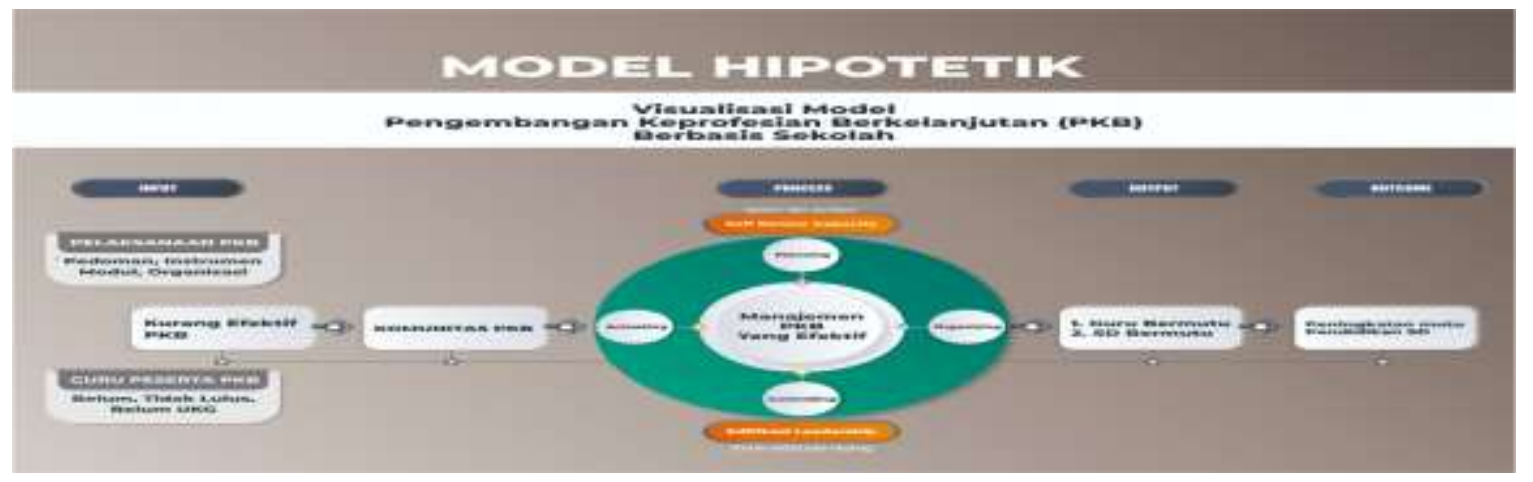

\section{Hasil Pengujian Model Pengembangan Keprofesian Berkelanjutan (PKB) Berbasis Sekolah}

Pengujian model dilakukan melalui proses Forum Group Discussion (FGD) yang terdiri dari beberapa ahli, praktisi, pengamat pendidikan dan peserta didik atau guru sekolah dasar di wilayah Kabupaten Garut Jawa Barat. Tujuan utama pengujian model melalui Forum Gorup Discussion (FGD) adalah untuk memperoleh interaksi data yang dihasilkan dari diskusi partisipan/responden untuk meningkatkan kedalaman berbagai aspek dari model pengembangan yang dihasilkan.

Berdasarkan proses pengujian yang dilakukan, maka peneliti memperoleh hasil sebagai berikut.

\section{Landasan Filosofis}

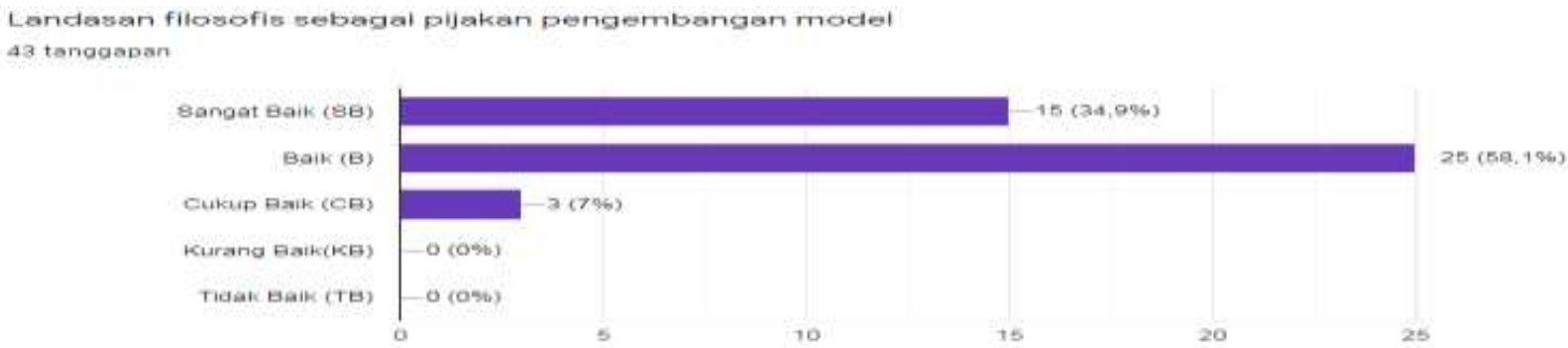

Berdasarkan hasil yang didapat sebagian responden pengujian model menilai landasan filosofis model memiliki kategori baik dengan persentase 58,1\% dan sebesar 34,9\% dengan persentase sangat baik. Hal ini menunjukkan bahwa gagasan model berdasarkan landasan filosofis memiliki kesesuaian dan berpotensi untuk dikembangkan sebagai pijakan dasar pengembangan model ini dilakukan. 


\section{Tujuan Model}

Tujuan yang merupakan arah untuk tercapainya model bila diterapkan

43 tanogapan

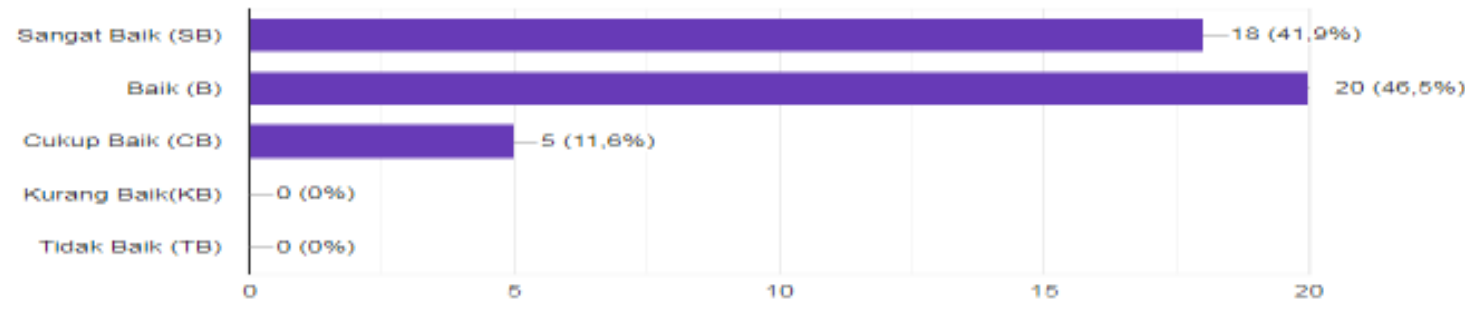

Tahapan selanjutnya ialah menentukan tujuan model, berdasarkan hasil yang diperoleh telah menujukkan bahwa responden memiliki penilaian sebesar 46,5\% dengan kategori baik, 41,9\% memilih penilaian sangat baik dan persentase sebesar $11,6 \%$ menilai cukup baik. Penilaian ini merupakan peringkat dan prioritas terbesar sampai yang terkecil dari setiap penilaian objek masing-masing responden. Dengan demikian, tujuan model yang disusun dapat berpotensi menjadi arah untuk tercapainya model bila diterapkan

\section{Rasionalisasi Model}

\section{Rasionallsas Model yang disusum}

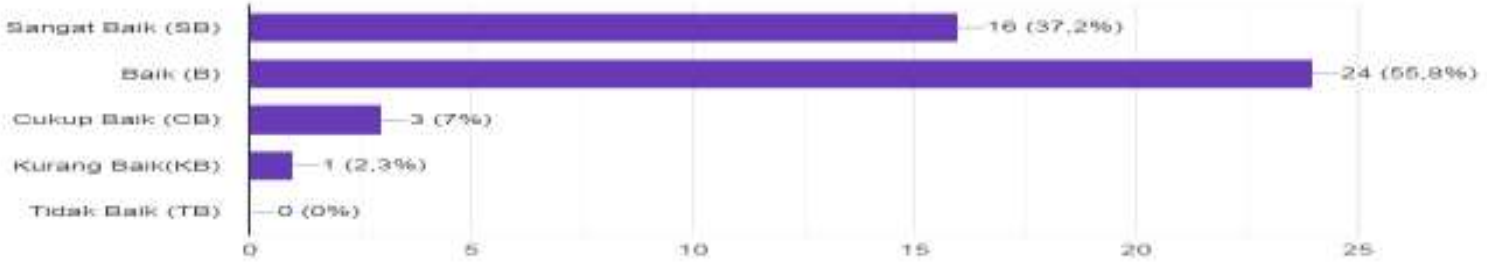

Berdasarkan masalah mendasar yang ditemukan, persentase penilaian para expert menunjukkan sebesar 55,8\% memiliki keriteria baik, serta sebesar 37,2\% memilih sangat baik. Namun dengan begitu, ketercapaian pada instrumen ini telah menunjukkan konvergensi atau konsensus bahwa instrumen ini sangat potensial untuk dikembangkan berdasarkan hasil penelitian untuk memerlukan solusi.

\section{Masalah Mendasar}

Masalah mendasar yang ditemukan dari hasil penelitian yang memeriukan solusi

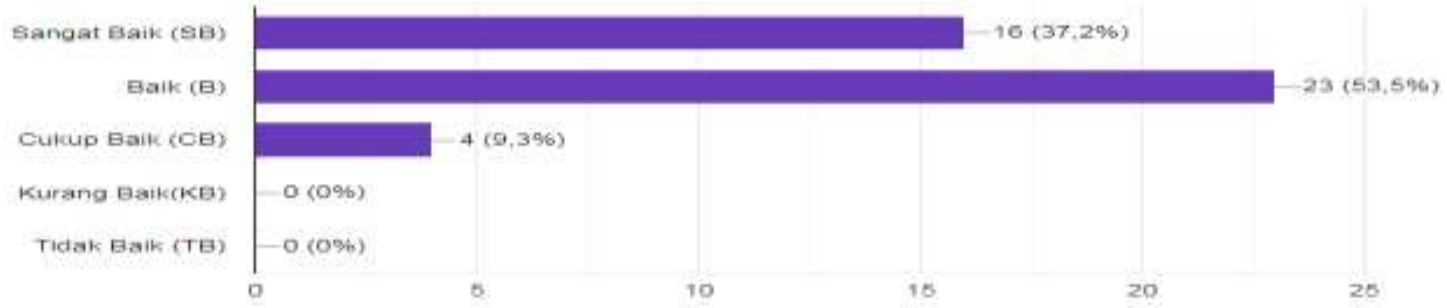

Berdasarkan persentase yang diperoleh, penilaian para responden terhadap masalah mendasar yang ditemukan pada model ini sebesar 53,5\% memilih penilaian baik dan sebesar $37,2 \%$ memilih penilaian sangat baik, selanjutnya persentase sebesar 9,3\% memilih penilaian cukup baik. 


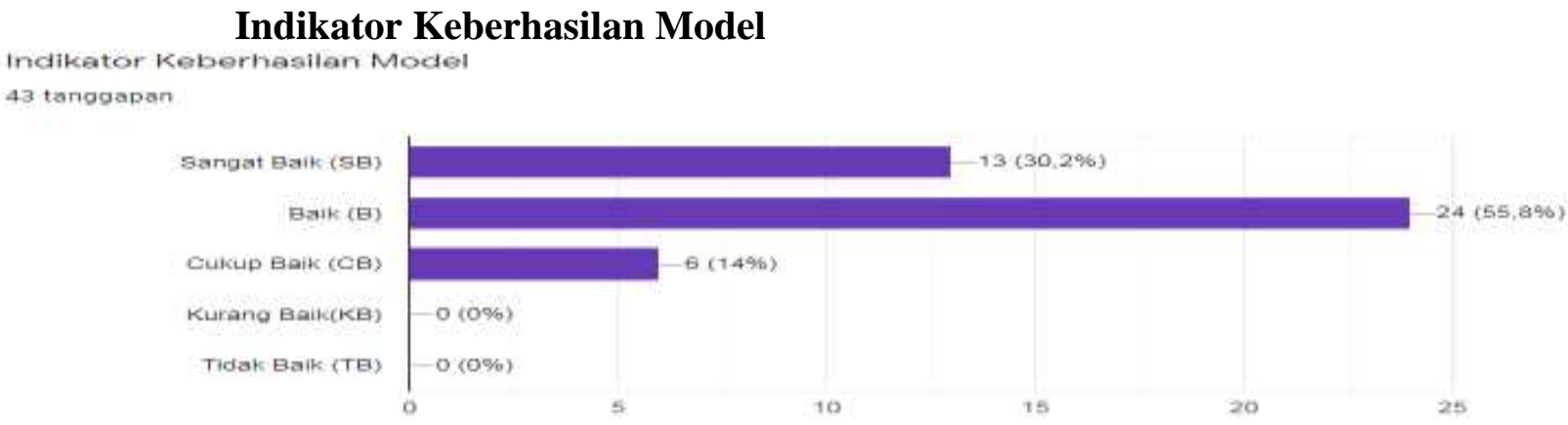

Sebagai tindak lanjut masalah mendasar yang ditemukan pada hasil penelitian, maka pada tahap selanjutnya peneliti menyusun beberapa alternatif yang menjadi salah satu solusi dalam memecahkan masalah yang telah dirumuskan. Hasil ini telah menunjukkan bahwa indikator keberhasilan model ini memiliki persentase sebesar 55,8\% dengan kategori baik, sedangkan sebagian responden memilih bahwa indikator keberhasilan model dengan kategori sangat baik sebesar $30,2 \%$, cukup baik dengan persentase sebesar $14 \%$. Dengan hasil tertinggi sebesar $57,1 \%$ telah memberikan hasil bahwa anggota penilai atau responden menilai bahwa indikator keberhasilan model yang disusun berpotensi baik untuk mewujudkan solusi yang diharapkan.

\section{Indikator Implementasi Model}

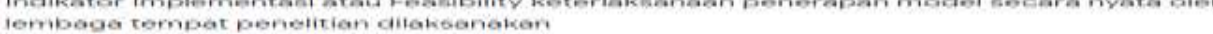
42 tangaspar

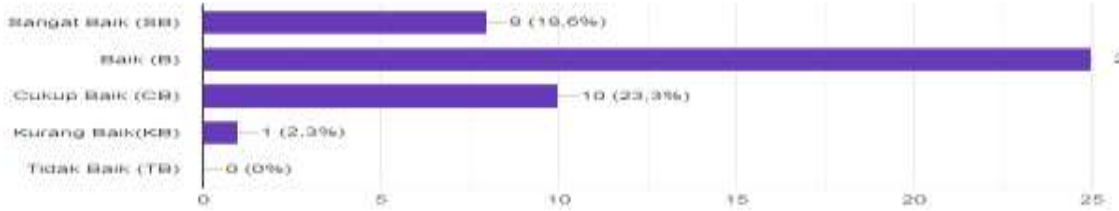

Tahapan selanjutnya adalah penyusunan indikator keberhasilan feasibility sebagai salah satu instrumen model untuk menilai sejauh mana model ini dapat diterapkan secara nyata oleh lembaga yang menjadi objek penelitian dilaksanakan. Berdasarkan hasil yang diperoleh, para responden memiliki penilaian yang cukup baik dengan persentase sebesar $23,3 \%$. Sedangkan sebagian lainya memberikan penilaian baik sebesar $58,1 \%$, adapun yang memiliki penilaian yang sangat baik terhadap instrumen ini sebesar 18,5\%. Dengan demikian, instrumen ini masih berpotensi untuk dikembangkan serta memiliki kelayakan untuk dapat diterapkan secara nyata di lembaga yang menjadi objek penelitian dilaksanakan.

\section{Visualisasi Tahapan Model}

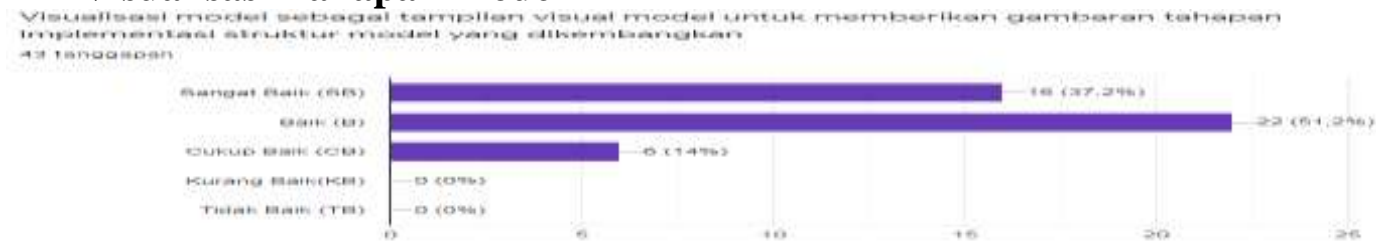

Visualisasi model menjadi isntrumen akhir yang menggambarkan seluruh tahapan implementasi model secara keseluruhan. Berdasarkan pengujian model yang sudah dilakukan melalui penilaian responden pengujian model, instrumen ini memiliki persentase sebesar 51,2\% dengan kategori baik, persentase sangat baik berada pada angka 37,2\%, sedangkan persentase cukup baik memperoleh sebesar $14 \%$. 


\section{Kesimpulan}

Program pengembangan keprofesian berkelanjutan (PKB) bagi guru sekolah dasar di Kabupaten Garut, secara umum belum dilaksanakan secara efektif sehingga belum berdampak secara luas terhadap peningkatan mutu guru.

Berdasarkan kesimpulan umum tersebut peneliti merumuskan kesimpulan yang bersifat khusus, sebagai berikut:

1. Eksisting Perencanaan dan pelaksanaan Program Pengembangan Keprofesian Berkelanjutan (PKB) oleh Guru Sekolah Dasar di Kabupaten Garut, lebih terfokus pada aspek kemampuan pengetahuan dan keterampilan pengembangan diri guru, namun aspek hasil publikasi ilmiah masih sangat rendah, demikan halnya dengan aspek karya inovatif yang di hasilkan oleh guru sekolah dasar juga masih minim.

2. Hasil dan dampak dari pelaksanaan Program Pengembangan Keprofesian Berkelanjutan (PKB) di sekolah dasar, di dominasi komponen pengembangan diri guru, sementara aspek publikasi karya ilmiah dan karya inovatif masih rendah.

3. Model hipotetik yang dihasilkan sebagai sebuah solusi yang ditawarkan peneliti dari kelemahan pelaksanaan Progam Keprofesian Berkelanjutan (PKB) bagi guru sekolah dasar selama ini adalah Model School Based Continous Professional Development (Model PKB berbasis pada Manajemen Sekolah). dengan menerapkan model PKB berbasis sekolah tersebut mendapatkan dua goal sekaligus, yakni membantu mempercepat meningkatan mutu guru dan juga meningkatkan mutu sekolah secara bersamaan.

\section{Saran dan Rekomendasi}

Peneliti merekomendasikan model alternatif baru dalam pelaksanaan PKB bagi guru sekolah dasar yang berbasis pada manajemen sekolah, untuk memperkuat pelaksanaan PKB yang selama ini berbasis komunitas KKG, sehingga kegiatan PKB menjadi lebih efektif, output-nya guru dan sekolah dasar mengalami peningkatan mutu, sementara outcome-nya mutu pendidikan dasar mengalami peningkatan. 


\section{Daftar Pustaka}

Aileen Kennedy. (2006). Models of Continuing Professional Development: a framework for analysis. Imaging, 31(2), 24. https://doi.org/10.33886/mj.v1i1.91

Aileen Kennedy. (2007). Continuing professional development (CPD) policy and the discourse of teacher professionalism in Scotland. Journal Research Papers in Education, 22(1), Pages 95-111. https://www.tandfonline.com/doi/full/10.1080/02671520601152128?scroll=top\&n eedAccess $=$ true

Asif, M., Searcy, C., Zutshi, A., \& Ahmad, N. (2011). An integrated management systems approach to corporate sustainability. European Business Review, 23(4), 353-367. https://doi.org/10.1108/09555341111145744

Bačáková, M., \& Closs, A. (2013). Continuing professional development (CPD) as a means to reducing barriers to inclusive education: Research study of the education of refugee children in the Czech Republic. European Journal of Special Needs Education, 28(2), 203-216. https://doi.org/10.1080/08856257.2013.778108

Cameron, M. (2006). Managing School Discipline and Implications for School Social Workers: A Re...: EBSCOhost. Children \& Schools, 28(4), 219227.

Cirocki, A., \& Farrell, T. S. C. (2019). Professional development of secondary school EFL teachers: Voices from Indonesia. System, 85, 102111. https://doi.org/10.1016/j.system.2019.102111

Dave Davis, D. A., \& McMahon, G. T. (2018). Translating evidence into practice: Lessons for CPD. Medical Teacher, 40(9), 892-895. https://doi.org/10.1080/0142159X.2018.1481285

Garrett, K. J. (2012). Managing school social work records. Children and Schools, 34(4), 239-248. https://doi.org/10.1093/cs/cds003

Geldenhuys, J. L., \& Oosthuizen, L. C. (2015). Challenges influencing teachers' involvement in continuous professional development: A South African perspective. Teaching and Teacher Education, 51, 203-212. https://doi.org/10.1016/j.tate.2015.06.010 Institute.

George R. Terry. (2005). Principles of Management. Alexander Hamiltorn

Guskey, T. R. (2004). Continuing professional development: does it make a difference? Nursing in Critical Care, 9(4), 167-172. https://doi.org/10.1111/j.1362-1017.2004.00071.x

Gustafsson, M., \& Taylor, S. (2018). Treating Schools to a New Administration: Evidence of the Impact of Better Practices in the System-Level Administration of Schools. Journal of African Economies, 27(5), 515-537. https://doi.org/10.1093/jae/ejy005

Indrasutanto, T. (2008). Strategi Pengembangan Sekolah Efektif untuk Implementasi Kurikulum Berbasis Kompetensi. Magister Scientiae, 24-Oktober, $100-102$.

Juneau Flor E.Julian \& Fred B.Ruiz. (2020). Continuing professional development (CPD) among educators in selected Colleges of Nursing: Perceived importance, impact, and challenges. Enfermería Clínica, 30(1), 60-64. https://doi.org/https://doi.org/10.1016/j.enfcli.2019.09.025

Laugharne, K., \& Price, C. (2009). 2.1 Continuing Professional 
Development (CPD) Strategy. Education for Primary Care, 20(sup1), 223-227. https://doi.org/10.1080/14739879.2009.11493852

Li, X., Han, Y., \& Kim, P. S. (2018). The development of China's public administration education. Teaching Public Administration, 36(2), 163-177. https://doi.org/10.1177/0144739418764537

Mansour, N., Heba, E. D., Alshamrani, S., \& Aldahmash, A. (2014). Rethinking the theory and practice of continuing professional development: science teachers' perspectives. Research in Science Education,.

Murphy, T. R. N., \& de Paor, C. (2017). Teachers' CPD and sectoral interests: Opportunities for convergence and divergence. Teaching and Teacher Education, 66, 242-249. https://doi.org/10.1016/j.tate.2017.04.018

Nolan, J. (2017).

The Oxford handbook of management theorists . Asia Pacific Business Review, 23(1), 152-153. https://doi.org/10.1080/13602381.2016.1148947

OECD. (2010). OECD (The Organization for Economic Cooperation and Development) Attracting, developing and retaining effective teachers.

Opfer, V. D., \& Pedder, D. (2011). Conceptualizing teacher professional learning. Review of Educational Research, 81(3), 376-407. https://doi.org/10.3102/0034654311413609

R.G, T. (2002). Professional development and teacher change. Teachers and Teaching: Theory and Practice, 8(January 2013), 381.

Raharjo, S. B., \& Yuliana, L. (2016). Manajemen Sekolah Untuk Mencapai Sekolah Unggul Yang Menyenangkan: Studi Kasus Di Sman 1 Sleman Yogyakarta. Jurnal Pendidikan Dan Kebudayaan, 1(2), 203. https://doi.org/10.24832/jpnk.v1i2.769

Ronald M, C. \& J. K. G. (2015). Functional Mentoring: A Practical Approach With. Journal Of Continuing Education In The Health Professions, 35(2), 131-138. https://doi.org/10.1002/chp

Rozensky, R. H., Grus, C. L., Fouad, N. A., \& McDaniel, S. H. (2017). Twenty-five years of education in psychology and psychology in education. American Psychologist, 72(8), 791-807. https://doi.org/10.1037/amp0000201

Sugrue, C., \& Mertkan, S. (2017). Professional responsibility, accountability and performativity among teachers: the leavening influence of CPD? Teachers and Teaching: Theory and Practice, 23(2), 171-190. https://doi.org/10.1080/13540602.2016.1203771

Sutapa, M. (2014). Membangun sekolah berbudaya mutu. 101-104.

van den Bergh, L., Ros, A., \& Beijaard, D. (2015). Teacher learning in the context of a continuing professional development programme: A case study. Teaching and Teacher Education, 47, 142-150. https://doi.org/10.1016/j.tate.2015.01.002

Van Veen, K., Zwart, R., \& Meirink, J. (2012). What makes teacher professional development effective? A literature review. In M. Kooy, \& K. van Veen (Eds.), Teacher learning that matters: International perspectives. 